\title{
STANDARDIZATION OF EUCALYPTUS GLOBULUS LEAVES AND CETRARIA ISLANDICA SLAN
}

\author{
Iryna Fito \\ Department of Technology of Biologically Active Compounds, Pharmacy and Biotechnology ${ }^{l}$ \\ irynadyakon@ukr.net \\ Nataliya Stadnytska \\ Department of Technology of Biologically Active Compounds, Pharmacy and Biotechnology ${ }^{l}$ \\ nataliyastadnytska@gmail.com \\ ${ }^{1}$ Lviv Polytechnic National University \\ 12 Bandera str., Lviv, Ukraine, 79000
}

\begin{abstract}
The aim. The aim of this study was to propose methods of standardization of Eucalyptus globulus leaves and Cetraria islandica slan by the main group of biologically active substances (BAS). This was done for further development of complex medicines based on Eucalyptus globulus leaves and Cetraria islandica slan.

These studies provide an opportunity for further development and standardization of extracts from these plants, and the main aim of this study is the development and standardization of a complex medicine.

Materials and methods. Thin layer chromatography was used to determine the presence of these markers. Quantitative values of these biologically active substances were determined by spectrophotometric method according to the relevant methods of the State Pharmacopoeia of Ukraine.

Results. Markers for the certification of Cetraria islandica and Eucalyptus globulus have been proposed in this study. Chlorophylls and 1,8-cineole were chosen as a marker for the study of Eucalyptus globulus, and polysaccharides were chosen as a marker for Cetraria islandica. The qualitative and quantitative content of these markers in the studied objects was studied.

Further research in this direction will be aimed at developing methods for control and standardization of water and alcohol extracts from these plants.

Conclusions. Biologically active substances in medicinal plant raw materials were studied. It is proposed to study extracts and finished products from Eucalyptus globulus leaves and Cetraria islandica slan using these methods.

The method of qualitative and quantitative determination of polysaccharides in Cetraria islandica slan is easy to apply and easily reproducible. It is important to be able to standardize Eucalyptus globulus leaves for essential oils and chlorophylls.

The biologically active substances-markers found in Eucalyptus globulus leaves and Cetraria islandica slan will be used for the development of herbal medicines, the standardization of which will be carried out for the same compounds.

Keywords: 1,8-cineole, chlorophylls, polysaccharides, phytochemical screening.
\end{abstract}

DOI: $10.21303 / 2504-5679.2021 .001659$

\section{Introduction}

The theoretical stage is important in the development of new herbal medicines. It is at this stage the markers are searched for further standardization of raw materials, extracts and finished products.

Modern physico-chemical methods allow to standardize herbal medicines by different classes of biologically active substances. However, scientists are increasingly facing the problem of standardization of plant products, which consist of several extracts.

As herbal medicines are popular among the population of Ukraine due to their effectiveness and safety, attention was focused on the selection of herbal ingredients for the new medicine. Among the official medicinal plants, a representative is Eucalyptus globulus which has a pronounced antimicrobial activity, and a member of the Parmeliaceae family - Cetraria islandica, which is a source of polysaccharides with mucolytic action. This is the reason why these plants were chosen as objects of the research $[1,2]$.

Cetraria islandica belongs to the leaf-bush lichens. In Ukraine, it grows almost throughout the territory in pine forests. Medicinal plant material is slan (Lichen islandicus) [2, 3]. 
The raw material has a weak peculiar odor and bitter-mucous taste. Lichen licorice contains up to $80 \%$ carbohydrates, $3 \%$ - proteins, $2 \%$ - fats, about $3 \%$ of pigments and $3-5 \%$ of lichen acids (cetraric (Fig. 1) and protocetraic acid (Fig. 2)), vitamins A, C, B 1 , B 12 , chromium salts, zinc, manganese, titanium, boron, copper, molybdenum, iron and iodine [2, 3].<smiles>CCOCc1c(O)c(C(=O)O)c(C)c2c1OC(=O)c1c(C)cc(O)c(C=O)c1O2</smiles>

Fig. 1. Cetraric acid<smiles>Cc1cc(O)c(C=O)c2c1C(=O)Oc1c(COC(=O)C=CC(=O)O)c(O)c(C(=O)O)c(C)c1O2</smiles>

Fig. 2. Protocetraic acid

The therapeutic effect of Cetraria islandica preparations is based primarily on the mucolytic action, antimicrobial activity and immunostimulatory properties of its extracts, as evidenced by the results of scientific studies. As Cetraria islandica also has protective properties, it can be used to prevent infectious and inflammatory diseases of the oral cavity. When there is a risk of colds, prophylactic use of Cetraria islandica, which can protect mucous membranes, significantly reduces the susceptibility of the respiratory tract to various infections. The polysaccharides contained in the medicine envelop the mucous membranes of the airways and effectively protect them from harmful external factors and various types of stimuli [2].

Eucalyptus globulus leaves contain resins, waxes, organic acids, tannins, essential oil, phenolic compounds, chlorophyll and others. Many works are devoted to the study of the components of essential oils [4]. 72 compounds were found in the essential oil of Eucalyptus globulus. Terpene compounds are represented by cyclic, acyclic and aromatic monoterpenoids and sesquiterpenoids [4, 5].

Eucalyptus globulus has antibacterial, antifungal, antiviral, astringent, hemostatic, anti-inflammatory and analgesic, antioxidant, antidiabetic, repellent action. Eucalyptus preparations are used to treat boils and other purulent infections (abscesses, phlegmons, osteomyelitis), ulcers, purulent and fresh wounds and open fractures; in the case of acute intestinal infections and dyspeptic disorders (vomiting, diarrhea, tingling, etc.), catarrh of the upper respiratory tract (cold, bronchitis, cough), throat infections, treatment of stomatitis and gingivitis $[7,8]$.

Eucalyptus globulus is most often standardized by the content of essential oil, in particular its component such as 1,8-cineole, as well as the number of chlorophylls. At the same time, the content of polysaccharides is informative for Cetraria islandica $[6,9]$.

Eucalyptus globulus leaves are most often standardized by markers of essential oils, in particular 1,8-cineole and chlorophylls. At the same time, Cetraria islandica slan can be rich in polysaccharides $[2,5,7]$.

The aim: assessment of qualitative and quantitative parameters for the raw material of Eucalyptus globulus and Cetraria islandica. These two plants were selected for the purpose of further preparation of extracts and development of a complex herbal remedy for the treatment of respiratory diseases. 


\section{Materials and methods}

Extracts of Cetraria islandica (extractant - drinking water) and Extracts of Eucalyptus globulus (extractant - ethanol 96 \%) were studied. Mettler Toledo AX 205 scales, Binder oven, Cary 100 spectrophotometer and Memmert water bath were used.

Determination of chlorophylls. The absorption spectrum of the test solution in the range from 600 to $700 \mathrm{~nm}$ should have a maximum absorption at a wavelength of $(649 \pm 3) \mathrm{nm}$. The results of detection of chlorophylls in the leaf of eucalyptus spherical are presented by UV-spectra in Fig. 3, the figure shows the control spectra of several series of raw materials (series 051120, 061120, 071120, 081120, 091120). The studies of several series was conducted for the accuracy of the results.

Determination of essential oils. Identification of essential oils was performed by thin layer chromatography (SPhU, 2.2.27).

Test solution. $3 \mathrm{~g}$ of crushed eucalyptus leaves weigh into a $25 \mathrm{ml}$ conical flask with ground cork, add $5 \mathrm{ml}$ of toluene $\mathrm{P}$ and make up to $10.0 \mathrm{ml}$ with the same solvent, decant and filter.

Comparison solution. $25 \mu \mathrm{l}$ of trans-nerolidol $\mathrm{P}$ and $50 \mu \mathrm{l}$ of cineole $\mathrm{P}$ were dissolved in toluene $\mathrm{P}$ and the volume of the solution was adjusted to $5.0 \mathrm{ml}$ with the same solvent.

Plate: TLC-plate with a layer of silica gel P $(5-40 \mu \mathrm{m})$ (or TLC plate with a layer of silica gel P $(2-10 \mu \mathrm{m})$ ). Mobile phase: ethyl acetate P - toluene P (5:95). Fig. 4 shows the sequence of zones on the chromatograms of the reference solution and the test solutions. The experiments were performed in parallel with the alcohol extract of eucalyptus by the same method.

Determination of polysaccharides. To determine the monomeric composition of polysaccharides performed acid hydrolysis with $10 \%$ sulfuric acid. Establishment of a qualitative monomeric composition of polysaccharides after hydrolysis was performed by the method. For the separation and identification of monosaccharides, down-chromatography in a solvent system of n-butanol-pyridine-water (6:4:3) was used in parallel with standard glucose samples. Glucose was detected by treating the chromatogram with a solution of aniline phthalate. Manifestation temperature $-100{ }^{\circ} \mathrm{C}$, duration of manifestation -10 minutes $[10,11]$.

Comparison solution. $2.5 \mathrm{mg}$ of hyperoside $\mathrm{P}$ and $2.5 \mathrm{mg}$ of rutin $\mathrm{P}$ are dissolved in $10 \mathrm{ml}$ of methanol R. Plate: TLC-plate with a layer of silica gel R.

Mobile phase: formic acid anhydrous $\mathrm{P}$ - glacial acetic acid $\mathrm{P}$ - water $\mathrm{P}$ - ethyl acetate $\mathrm{P}(11: 11: 27: 100)$.

Detection: the plate was sprayed with a solution of $10 \mathrm{~g} / 1$ of aminoethyl ester of diphenylboronic acid $\mathrm{P}$ in methanol $\mathrm{P}$, then a solution of $50 \mathrm{~g} / 1$ of macrogol $400 \mathrm{P}$ in methanol $\mathrm{P}$ and dried in air for $30 \mathrm{~min}$. Viewed in UV light at a wavelength of $365 \mathrm{~nm}$ (Fig. 5). The experiments were performed in parallel with an aqueous extract of cetraria by the same method.

Chromatographic profile. The chromatographic profile of Eucalyptus globulus leaves is also presented. To do this, to $5 \mathrm{~g}$ of leaves was added $50 \mathrm{ml}$ of ethanol $96 \% \mathrm{P}$ and extracted for 1 hour, then defended for 30 minutes

Next the comparison solutions were prepared. $0.0100 \mathrm{~g}$ of aromadren, globulol, 1,8-cineole, terpen-4-ol were placed in volumetric flasks with a capacity of $10 \mathrm{ml}$, dissolved in $10 \mathrm{ml}$ of ethanol $\mathrm{P}$, the volume of the solution was adjusted to $10.0 \mathrm{ml}$ with ethanol P. After that $1 \mathrm{ml}$ of each of the reference solution was placed in a $10 \mathrm{ml}$ volumetric flask and adjusted to the mark with $96 \%$ ethanol.

Used a column with a size of $30 \mathrm{~m} \times 0.53 \mathrm{~mm}$ filled with sorbent macrogol $20000 \mathrm{P}$ with a layer thickness of $1 \mu \mathrm{m}$ (HP-INNOWax, catalog number HP 19095N-123), carrier gas - helium for chromatography, detector.

The efficiency of the chromatographic column calculated from the peaks of 1,8-cineole, aromadren, globulol, terpen-4-ol from the chromatograms of the reference solutions, respectively, must be at least 10,000 theoretical plates (Fig. 6).

Determination of the quantitative content of essential oil. Eucalyptus leaves were ground to the size of particles passing through a sieve with holes with a diameter of $2 \mathrm{~mm}$. The essential oil content was determined in $10 \mathrm{~g}$ of crushed raw material (SPhU, 2.8.12). The results are shown in Table 1.

Determination of the quantitative content of chlorophyll. Determination of chlorophyll content was carried out by spectrophotometric method. 
To calculate the concentration of chlorophyll in the extract, its optical density was determined spectrophotometrically (spectrophotometer U-2810, Japan) at a wavelength corresponding to the maxima of the absorption spectrum of the studied pigments in this solvent. For chlorophyll A in $96 \%$ ethanol the maximum absorption is $\lambda=665 \mathrm{~nm}$, for chlorophyll $\mathrm{B}-\lambda=649 \mathrm{~nm}$. The reference solution was $96 \%$ ethanol. $2 \mathrm{ml}$ of solution was placed in a cuvette. Measurements were performed in triplicate, the average value was used for calculation.

The concentration of chlorophyll was calculated by the formulas (1-2):

$$
\begin{aligned}
& C_{\text {chl.a }}=13.70 \cdot A_{665}-5.76 \cdot A_{649} ; \\
& C_{\text {chl.b }}=25.80 \cdot A_{649}-7.60 \cdot A_{665},
\end{aligned}
$$

$\mathrm{A}_{649 \text { average }}$ - optical density of the solution at a wavelength of $649 \mathrm{~nm} ; \mathrm{A}_{665}$ average - optical density of the solution at a wavelength of $665 \mathrm{~nm}$.

Data of the total chlorophyll content in the extract of Eucalyptus globulus are presented in Table 1.

Determination of the quantitative content of polysaccharides. The tests were performed by adsorption spectrophotometry in the ultraviolet and visible regions, in accordance with the requirements (SPhU, 2.2.25).

Stock solution 1. $3.0 \mathrm{~g}$ of LRS crushed $(1 \mathrm{~mm})$ was placed in a conical flask with a section of $250 \mathrm{ml}$, add $75 \mathrm{ml}$ of water $\mathrm{P}$ and stirred for $30 \mathrm{~min}$ at $80^{\circ} \mathrm{C}$ under reflux, cooled. Centrifuged for $10 \mathrm{~min}$ at a rate of $6000 \mathrm{rpm}$ and decanted into a volumetric flask with a capacity of $250 \mathrm{ml}$ through 6 layers of gauze, pre-soaked in water R. Extraction was performed with 3 portions of water R.

Acid hydrolysis of polysaccharide fractions was performed using a $10 \%$ solution of sulfuric acid for 5-6 hours. The obtained filtrate was neutralized with barium carbonate according to the universal indicator and concentrated. Arabinose, galactose, glucose, xylene, rhamnose and fructose (concentration of all solutions was $1 \mathrm{mg} / \mathrm{ml}$ ) were used as standard samples of monosaccharides.

Test solution. $2.0 \mathrm{ml}$ of stock solution 1 was placed in a conical flask was added $5.0 \mathrm{ml}$ of o-toluidine reagent.

Stock solution 2. $0.02 \mathrm{~g}$ of glucose $\mathrm{P}$ was dissolved in water $\mathrm{P}$ and adjusted with water $\mathrm{P}$ to $100.0 \mathrm{ml} .10 \mathrm{ml}$ of the resulting solution was transferred into a $20 \mathrm{ml}$ volumetric flask and made up to the mark with water R.

Comparison solution. $2.0 \mathrm{ml}$ of stock solution 2 was placed in a conical flask and $5.0 \mathrm{ml}$ of o-toluidine reagent was added. Heated in a boiling water bath for 8 minutes. Cooled in a cold water bath. Compensation solution. $2.0 \mathrm{ml}$ of water $\mathrm{P}$ was placed in a conical flask was added $5.0 \mathrm{ml}$ of o-toluidine reagent. The content of sugars $(X)$ in terms of glucose in percent is calculated by the formula (3):

$$
X=\frac{A_{1} \cdot m_{0} \cdot 250 \cdot 10 \cdot 100}{A_{0} \cdot m_{1} \cdot 100 \cdot 20}=\frac{A_{1} \cdot m_{0} \cdot 250}{A_{0} \cdot m_{1} \cdot 2},
$$

where $A_{1}$ - the optical density of the solution; $A_{0}$ - optical density of glucose; $m_{1}-$ a sample of elephant moss; $m_{0}$ - a portion of glucose.

The results are in Table 1.

\section{Results}

Chlorophylls had red fluorescence in UV-light. The results of detection of chlorophylls in Eucalyptus globulus leaf are presented by UV-spectra in Fig. 3.

The results of the identification of 1,8-cineole are shown by thin layer chromatography in Eucalyptus globulus leaves and polysaccharides in Cetraria islandica slan are shown below in the chromatograms (Fig. 4, 5).

The chromatographic profile of the study of eucalyptus leaves is presented in Fig. 6.

The results on the quantitative content of essential oils, chlorophylls in the Eucalyptus globulus leaves and polysaccharides in Cetraria islandica slan are presented in Table $\mathbf{1 .}$ 




Fig. 3. UV-spectrum of chlorophyll detection in different series of Eucalyptus globulus leaves



Fig. 4. Copy of Eucalyptus globulus leaf chromatogram, Merck plate, HX899621 series: 1 - tested solution of Eucalyptus globulus leaf; 2 - tested solution of Eucalyptus globulus liquid extract; 3 - comparison solution of 1,8-cineole

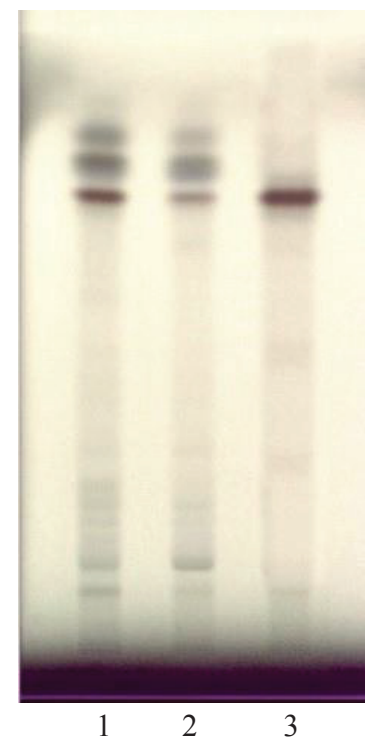

Fig. 5. Chromatograms of detection of polysaccharides in Cetraria islandica slan: 1 - tested solution of Cetraria islandica slan; 2 - tested solution of Cetraria islandica liquid extract; 3 - glucose comparison solution 




Fig. 6. Chromatographic profile of Eucalyptus globulus leaves

Table 1

The results of determining the quantitative content of BAS in the studied samples of Eucalyptus globulus and Cetraria islandica

\begin{tabular}{cccc}
\hline Research of quantitative content & Object of study & Results of the research & Research method \\
\hline Essential oils & Eucalyptus globulus & $2.25 \%$ & Spectrophotometry, SPhU, 2.8.12 \\
Chlorophylls & Eucalyptus globulus & $0.081 \mathrm{mg} / 1$ & Spectrophotometry, SPhU, 2.8.12 \\
Polysaccharides & Cetraria islandica & $1.08 \%$ & Adsorption spectrophotometry, SPhU, 2.2.25
\end{tabular}

\section{Discussion}

The author Koshovyi O. identified chlorophylls in the chloroform fraction of water-alcohol extract from Eucalyptus leaves using two-dimensional TLC, chlorophyll A and B had red fluorescence in UV light [5]. This study shows that Eucalyptus globulus leaves can be identified not only by the presence of chlorophylls, but also by essential oils. During the study, the appearance of chlorophylls on the spectrum was clearly observed. It is proposed to standardize the extracts and the finished medicine for these BAS. Quantitatively in the Eucalyptus globulus was found the same instead of the group BAS. The proposed methods are practical and widely used.

Cetraria islandica is proposed to be standardized for the content of polysaccharides [12, 13]. In Huneck S.'s research, the identification of biologically active substances in lichens was also performed by thin-layer chromatography $[14,15]$. Regarding the method of quantitative determination, it is possible to consider in addition to the method of absorption spectrophotometry, to use the gravimetric method [16, 17]. Author Basaraba R. Yu. offers a gravimetric method to accurately quantify compounds in plant raw materials [17, 18].

As we can see, in order to provide similar biologically active compounds in extracts or already finished product on the basis of Eucalyptus globulus leaves and polysaccharides in Cetraria islandica a appropriate method of technological process of manufacturing should be developed $[19,20]$.

Study limitations. The studies did not include samples of medicinal plant raw materials from different regions of the world.

Prospects for further research. Standardization of extracts and finished products from this plant raw material for traceability of BAS in the sequence: plant raw material-extractfinished medicine. 


\section{Conclusions}

1. To determine the presence of these BAS used thin layer chromatography. A characteristic spot of 1,8-cineole was found in the Eucalyptus globulus and a glucose was found in the Cetraria islandica.

2. Quantitative values of these BAS were determined by spectrophotometric method according to the relevant methods of the State Pharmacopoeia of Ukraine. The content of essential oil in Eucalyptus globulus was $2.250 \%$, and the content of chlorophyll A and B was $0.081 \mathrm{mg} / \mathrm{l}$. The content of polysaccharides in the extract of Cetraria islandica was equal to $1.080 \%$.

3. The markers proposed for the certification of Cetraria islandica and Eucalyptus globulus can be used to standardize the complex extract from these plants. It is advisable to further study the complex extract.

\section{Conflict of interests.}

The authors declare that they have no conflicts of interest.

\section{References}

[1] Osawa, K., Yasuda, H., Morita, H., Takeya, K., Itokawa, H. (1995). Eucalyptone from Eucalyptus globulus. Phytochemistry, 40 (1), 183-184. doi: http://doi.org/10.1016/0031-9422(95)00233-w

[2] Katalinic, V., Milos, M., Kulisic, T., Jukic, M. (2006). Screening of 70 medicinal plant extracts for antioxidant capacity and total phenols. Food Chemistry, 94 (4), 550-557. doi: http://doi.org/10.1016/j.foodchem.2004.12.004

[3] Bailey, C. (2008). Metformin: effects on micro and macrovascular complications in type 2 diabetes. Cardiovascular Drugs and Therapy, 22 (3), 215-224. doi: http://doi.org/10.1007/s10557-008-6092-0

[4] Kim, J.-P., Lee, I.-K., Yun, B.-S., Chung, S.-H., Shim, G.-S., Koshino, H., Yoo, I.-D. (2001). Ellagic acid rhamnosides from the stem bark of Eucalyptus globulus. Phytochemistry, 57 (4), 587-591. doi: http://doi.org/10.1016/s0031-9422(01)00146-7

[5] Koshovyy, O., Komissarenko, A., Kovaleva, A., Mudryk, I. (2005). Microelement, amino acid and polysaccharide composition of eucalyptus leaves. Phytotherapy, 3, 59-62.

[6] State Pharmacopoeia of Ukraine. Vol. 2 (2018). Kharkiv: State Enterprise «Ukrainian Scientific Pharmacopoeial Center for Drug Quality», 416. Available at: http://sphu.org/wp-content/uploads/2018/07/Gfu2.3.pdf

[7] Guidelines of the Ministry of Health of Ukraine «Drugs. Good laboratory practice: ST-N MOH 42-6.0: 2008 (2012). Kyiv, 27. Available at: https:/compendium.com.ua/uk/clinical-guidelines-uk/standartizatsiya-farmatsevtichnoyi-produktsiyi-tom-2/ st-n-mozu-42-6-0-2008/

[8] Pavlyuk, I., Stadnytska, N., Jasicka-Misiak, I., Wieczorek, P., Zagoriy, G., Brezvyn, O. et. al. (2015). Study of biological activity of secondary extract from oregano herbs waste qoriganum vulgaret. Ukrainian Biopharmaceutical Journal, 1 (36), 21-24. Available at: http://91.234.42.22/bitstream/123456789/7389/1/UBFZh1-15-3.pdf

[9] Kovalev, V., Marchyshyn, S., Hvorost, O. et. al.; Kovalev, V., Marchyshyn, S., Hvorost, O., Isakova, T. (Eds.) (2014). Workshop on the identification of medicinal plant raw materials. Ternopil: TDMU, 264. Available at: https://dspace.nuph.edu.ua/ handle/123456789/21239

[10] Assunção, M. F. G., Amaral, R., Martins, C. B., Ferreira, J. D., Ressurreição, S., Santos, S. D. et. al. (2016). Screening microalgae as potential sources of antioxidants. Journal of Applied Phycology, 29 (2), 865-877. doi: http://doi.org/10.1007/ s10811-016-0980-7

[11] Grodzinskiy, A. (1990). Medicinal Plants: Encyclopedic Handbook. Kyiv: Heads edit URE.

[12] Diakon, I. V., Stadnytska, N. E., Hubytska, I. I., Lylo, V. V., Petrykevych, V. R. (2017). Using of iceland moss in treatment of infectious respiratory diseases and prospects of creating new drugs based on it. Visnyk Natsionalnoho universytetu «Lvivska politekhnika». Serie: Khimiia, tekhnolohiia rechovyn ta yikh zastosuvannia, 868, 234-241. Available at: http://ena.lp.edu. ua:8080/handle/ntb/40646

[13] Assessment report on Eucalyptus globulus Labill., folium (2012). The European Medicines Agency (EMA). Available at: https:/www.ema.europa.eu/en/documents/herbal-report/draft-assessment-report-eucalyptus-globulus-labill-folium_en.pdf

[14] Huneck, S., Yoshimura, I. (1996). Identification of Lichen Substances. Springer, 11-123. doi: http://doi.org/10.1007/978-3-64285243-5_2

[15] Marxen, K., Vanselow, K., Lippemeier, S., Hintze, R., Ruser, A., Hansen, U.-P. (2007). Determination of DPPH Radical Oxidation Caused by Methanolic Extracts of Some Microalgal Species by Linear Regression Analysis of Spectrophotometric Measurements. Sensors, 7 (10), 2080-2095. doi: http://doi.org/10.3390/s7102080 
[16] Basaraba, R. (2019). Pharmacognosy study of common pussytoes (Antennaria dioica) in order to develop new medicines. Lviv, 184. Available at: http://nauka.meduniv.lviv.ua/wp-content/uploads/2019/10/\%D0 \%94 \%D0 \%B8 \%D1 \%81.- \%D0 \%91 \%D0 $\%$ B0 \%D1 \%81 \%D0 \%B0 \%D1 \%80 \%D0 \%B0 \%D0 \%B1 \%D0 \%B0.pdf

[17] Hardel, D. K., Sahoo, L. (2011). A review on phytochemical and pharmacological of Eucalyptus globulus: a multipurpose tree. International Journal of Research in Ayurveda and Pharmacy, 32, 1527-1530. Available at: http://www.ijrap.net/admin/php/ uploads/648_pdf.pdf

[18] Renedof, O., Otero, J., Mira, J. (2000). Oile essentielle de Eucalyptus globulus L. de Contabrie. Variation fn cours de la distillation. Plant. med. et phetother, 1 (24), 31-38.

[19] Martines, M. (2006). Estudio preliminar de los aceites esenciales de Evcalyptus introducides en la region de Topes de Callantes. Rev. cub. Farm, 2, 159-168.

[20] Chueshov, V., Gladui, E., Sayyko, V. et. al. (2013). Technology of medicines for industrial production. Part 1. Kharkiv: NFaU, 694. Available at: https://dspace.nuph.edu.ua/handle/123456789/23564

Received date 02.01.2021

Accepted date 11.02.2021

Published date 16.02.2021

(C) The Author(s) 2021

This is an open access article under the CC BY license (http://creativecommons.org/licenses/by/4.0).

How to cite: Fito, I., Stadnytska, N. (2021). Standardization of eucalyptus globulus leaves and cetraria islandica slan. EUREKA: Health Sciences, 2, 56-63. doi: http://doi.org/10.21303/2504-5679.2021.001659 